\title{
EFFECTIVE LEARNING ENVIRONMENTS: IS THERE ALIGNMENT BETWEEN THE IDEAL, THE ACTUAL, AND THE STUDENTS' PERSPECTIVE?
}

\author{
Nancy Nelson, Robert Brennan \\ Schulich School of Engineering, University of Calgary \\ nancy.nelson1@ucalgary.ca rbrennan@ucalgary.ca
}

\begin{abstract}
The overarching principles of effective educational practice in higher education define the characteristics of an effective learning environment. Institutions of all sizes have demonstrated that it is possible to increase student success and add value to the learners' experiences by applying these principles. This qualitative study explores the alignment between the ideal learning environment, the actual undergraduate engineering experience as defined by engineering educators, and the learners' perspective.

Building on the benchmarks of effective learning environments, students were asked to complete an online survey based on the Stop, Start, Continue method for acquiring formative feedback. Thematic analysis identified five themes: focus on learning, supported instruction, quality of teaching, student engagement, and other related items including academic rigour and strong relationships between students, instructors, and staff.

Students indicate that their primary learning environment is teacher-directed and lecture-based. This is aligned with the current practices identified by engineering educators, but only partially in line with those of an effective learning environment. Coded items indicate that many students have sub-optimal motivational outlooks, but feel their ability to survive and thrive is improved when they are more involved in their learning and are supported in a more student-centred learning environment. They value instructors who provide clear and accurate resources, and who are supportive through actions both in and out of the classroom. Engineering educators can use these insights to better align their teaching practices with the principles and practices of effective learning.
\end{abstract}

Keywords: effective educational practice; effective learning environments; student success; student motivation; student engagement

\section{INTRODUCTION}

Establishing an effective learning environment for undergraduate students requires input from many stakeholders. Accrediting bodies have a say in what attributes a graduate should have, institutions define a mission and establish an educational philosophy, central services provide academic and social support, departments develop an integrated curriculum, instructors deliver the curriculum, and students learn. Unfortunately, this is not always the case, particularly at the level where instructors and learners are involved. It is possible, however, to move from one's current learning environment to one that is more effective.

To determine just how effective the Canadian undergraduate engineering learning experience is for today's learners, it is important to examine the alignment of the ideal and the actual as defined by engineering educators and learners. This paper compares the results of a qualitative study of undergraduate engineering students' perceptions of what would improve their engagement and chances of success in their chosen programs to those of evidence-based effective educational practices, and the actual educational practices as reported by their instructors.

\section{BACKGROUND}

It is said that learning environments have "both a direct and indirect influence on student learning, including their engagement in what is being taught, their motivation to learn, and their sense of well-being, belonging, and personal safety" [1]. This section examines the literature on effective learning environments, and students' engagement with, and perceptions of, their post-secondary experience.

\subsection{Effective Learning Environments}

Bransford and his colleagues suggest that an effective learning environment requires the alignment of what is taught, how it is taught, and how it is assessed [2]. They offer four perspectives on learning environments: (1) 
learner-centeredness where students construct their own meaning from previous knowledge and current academic tasks, (2) knowledge-centeredness where students learn in ways that help establish integrated disciplinary knowledge, (3) assessment-centeredness that provides opportunities for feedback and revision of knowledge, and (4) community-centeredness where shared norms and practices establish values and standards for learning. They suggest that learning environments are most effective when all four perspectives align and mutually influence one another.

A review of the extensive literature on effective educational practices identifies a number of benchmarks that are currently used to define and measure effective learning [3][4][5][6][7][8][9]. These can be categorized into six broad themes for ensuring student success and value-added learning: (1) an appropriate level of academic rigour, (2) a focus on learning, (3) supported instruction, (4) quality of teaching, (5) development of strong relationships, and (6) student engagement.

Draeger and his colleagues define academic rigour as the overlap of four primary dimensions: active learning, meaningful content, higher-order thinking, and appropriate expectations. They suggest the "ultimate goal is for students to be actively learning meaningful content with higher-order thinking at (or above) the appropriate level of expectation" [10]. The focus of the learning theme consolidates the benchmarks associated with active and collaborative learning, learning strategies, reflective and interactive learning, higher order thinking, skills development and quantitative reasoning. Each of these directly involves students in, and with, their learning.

The supported instruction theme includes the teaching methods and materials used to support student learning. This includes the benchmarks associated with educational experiences in the classroom, learning opportunities, learning resources, and assessment and feedback. Quality of teaching includes benchmarks related to effective teaching practices, teaching quality, and instructional clarity, while the development of strong relationships consolidates items associated with faculty-student interactions, diversity, student support, learning communities, student voice, and organization and management. As proposed by Kuh and his associates [11], student engagement has two key components: the amount of time and effort students put into their studies and activities that contribute to their success as a student, and the ways in which an institution supports student success.

A 2018 study of the state of engineering education in Canada shows that most engineering classes are teacherdirected and lecture-based [12]. Some educators use active and collaborative learning, but others identify barriers such as student resistance, low teaching evaluations, time commitment vs. benefit, and access to resources as reasons for their more traditional methods.
These educational practices are only somewhat aligned with the benchmarks established for an effective learning environment. Supported instruction is but one of six benchmarks. There is also a need to consider student learning, the quality of teaching, relationships, and student engagement.

\subsection{Student Engagement and Perceptions}

Undergraduate students at many post-secondary institutions around the world participate in annual student engagement surveys. The National Survey of Student Engagement (NSSE) is administered to over 275,000 students across North America, the Quality Indicators for Learning and Teaching (QILT) surveys over 200,000 students in Australia, and the UK's National Survey of Students surveys another 500,000 graduating students. These student engagement surveys measure variations of the six generalized benchmarks for ensuring student success and value-added learning.

Results of these surveys report that engineering students are generally less positive about their learning experiences than their peers in other areas of study. In the most recent NSSE report, Canadian senior engineering students' engagement in four of ten benchmarks (learning strategies, effective teaching practices, quality of instruction, and supportive environment) was lower than that of their peers in all other disciplines. Their engagement was second or third lowest in three additional benchmarks (reflective and integrated learning, studentfaculty interaction, and higher order learning). The remaining three benchmarks (qualitative reasoning, collaborative learning, and discussion with diverse others) were ranked highest among the areas of study.

This finding is not unique to Canadian engineering students. Similar results were reported by American students with eight of the ten benchmarks ranked either last or second last [5], and by Australian students who reported engagement levels lower than their peers in 20 other areas of study [6].

Institutions can glean important insights into student perspectives about their learning from these national engagement surveys. But the questions that are asked typically represent the interests of administrators and educators, not those of the students [13]. These surveys also miss data on the students' perception of their learning environment. van den Bogaard found this to be true in her synthesis of literature on student success in engineering education [14]. Boles and Whelan's work examining the barriers to student success in engineering education [15] explored the students' perspective through focus groups, and found that the learning environment is a major influence on self-regulated learning and student success. Their key findings indicate that learners should be actively involved in their learning, and the quality of interaction between educators and students has a significant impact on the student experience. 
This qualitative study explores what undergraduate engineering students believe contributes to, or impedes, their learning experience. It seeks to answer the following questions: (1) is there alignment between an effective learning environment, the undergraduate engineering experience as defined by engineering educators, and the learners' perspective, and (2) what strategies can engineering educators implement to create effective learning environments?

\section{METHODOLOGY}

An e-mail was sent to all 3187 full- and part-time undergraduate engineering students attending a mid-size Canadian engineering school inviting them to complete an online survey entitled 'A Snapshot of Canadian Engineering Education: What Do Engineering Students Think about their Classroom Experiences'. The survey was sent at the beginning of the winter semester and there were no incentives provided for the students for completing the survey.

The survey was modeled on the 'Stop, Start, Continue' method that is often used for gathering constructive qualitative feedback from students in higher education [16][17]. The snapshot survey was divided into two main sections: (1) Basic Information, and (2) Thoughts about your Undergraduate Engineering Classes. The 'Basic Information' section gathered demographics, while the 'Thoughts' section contained six questions. The first three questions asked students to identify what they would like their instructors to start ("List things that your professors or instructors might start doing in class that you would find helpful"), stop ("List things you wish your professors or instructors would stop doing in class because they are not helpful"), and continue doing ("List things that your professors or instructors should keep doing in class because you find them helpful"). The next two questions asked students to describe their best and worst experiences in the classroom. The final question asked them to identify how their engineering classes helped or hindered their learning. Only the Start, Stop, and Continue responses are considered in this analysis.

\subsection{Data Analysis}

Of the 3187 engineering students contacted, 262 participated in this research study $(8.2 \%)$. Of the 262 respondents, 100 chose not to answer any questions beyond the Basic Information section. The demographics of those non-responders are excluded from the following breakdown.

$46.4 \%$ of the respondents were female and $51.0 \%$ male. For all other gender-related responses there were insufficient numbers to ensure anonymity. This distribution is not representative of the gender breakdown within the school ( $25.5 \%$ female, $74.5 \%$ male).
$31.8 \%$ of the respondents indicated they were registered in first year, $21.9 \%$ in second year, $23.8 \%$ in third year, $13.2 \%$ in fourth year, and $9.3 \%$ in fifth year, having returned to their studies from a year-long internship. $3.3 \%$ of the respondents were international students. The actual distribution of students by year is $24.3 \%$ in year $1,25.9 \%$ in year $2,18.6 \%$ in year 3 , and $31.2 \%$ in years 4 and 5 , with $87.7 \%$ being domestic students, and the remaining $12.3 \%$ international.

Deductive thematic analysis was used to code the student responses. Theory triangulation ensured the validity of the categorizations, with the codes resulting from the benchmarks employed in student engagement surveys being very similar to those coded using the elements of curriculum defined within the Universal Design for Learning [18]. 437 items were coded from the Start responses, 317 items from the Stop responses, and 393 from the Continue responses.

Initial coding analysis produced 16 open codes for the student responses (e.g. direct instruction, resources, presentation methods, evaluation, etc.). These 16 open codes were then recoded to form five definitional categories that line up with the benchmarks for effective learning: focus on learning, supported instruction, quality of teaching, student engagement, and other related items including academic rigour and strong relationships.

\section{RESULTS}

This section reports on the perceptions of the students who participated in the study. It reflects aspects of the current undergraduate engineering learning environment as compared to the benchmarks of effective learning environments.

\subsection{Focus on Learning}

Approximately $15 \%$ of the coded items related to ways in which students are involved in, and with, their learning. Three themes emerged from these items: (1) practice problems, (2) formative assessments, and (3) interactivity in the classroom.

Students clearly identified the desire to be given lots of practice problems. Comments like "I think focused practice problems are great", "explain why you do a step. The reasoning helps greatly in understanding how to solve a problem", and "Though we usually do have practice and example problems, I feel that having more practice would help me remember the concepts we learn in the long run" represents the overall sentiment that students feel practice problems (preferably with solutions) are instrumental to their learning.

Students also appear to place value on low- or nostakes formative assessments such as assignments and weekly quizzes. Comments such as "using frequent lowconsequence quizzes to encourage students to stay on top of things", and "Having assignments/quizzes that are not 
worth marks, so that you can know your honest level of understanding without suffering a grade penalty" suggest that many students truly want to learn.

Learners have mixed thoughts on the use of interactive, technology-based, student engagement tools in the classroom. This is reflected in comments ranging from using tech "to keep kids involved", and "I understand the benefit of using it but I already focus on problem exercises in class", to "not wasting time on things like ... surveys or other time killers". They do, however, recognize that in-class discussion with their peers helps them understand new concepts. They would like to "discuss the possible answers with each other" and appreciate instructors who encourage "discussion of questions/course material in lecture". The few comments related to flipped learning were not positive.

The majority of comments related to student learning seem to indicate that the undergraduate engineering experience continues to be teacher-directed and lecturebased, supported by traditional learning opportunities such as practice problems, assignments, and quizzes.

\subsection{Supported Instruction}

Almost $70 \%$ of the coded items related to teaching and learning efforts that are done for the student. Three themes emerged from these items: (1) the lecture experience, (2) materials provided to the students, and (3) the academic support provided to the students.

Students seem accepting of a teacher-centred lecturebased classroom. This may be because the majority of their classes are delivered this way and students accept and/or are conditioned to these more traditional methods. They do, however, have definite opinions about which techniques and strategies within this model are most helpful to their learning. These include: authenticity, expert practices, depth of learning, relevant content, scaffolded learning, and teaching practices.

Students clearly indicate that they want to know why topics and concepts are important and where they are applied. Comments such as "More relating class concepts to functional applicability in practice" and "Providing relevant detail on what we are learning is practically used for" suggest that authenticity will help them find meaning in what they are learning. Some students recognize the importance of thinking like an expert, and want their instructors to break those skills down. Statements like "the most precious knowledge a professor can impart on us is his decades of experience on how to simplify enormous problems" reflect the desire to understand the process, not simply know how to answer a question.

Some students enunciate the need for more opportunities to learn. Some request that instructors "teach more material in class" and others want "greater depth, please. I am here to learn". That said, they want that content to be directly related to the course assessments. Many students echoed the ideas expressed by one who stated "It may feel like explaining everything about a concept is helpful, in reality forgoing crucial time on the parts that we need to know for exams or assignments is hurting our understanding. Some may feel differently, but I feel that, for example, knowing the proof for the equation, especially when the proof is long/difficult, is unimportant". For these students the desire to survive seems to take precedence over the need to thrive.

Many students requested a more graduated approach to learning that reviews and builds on assumed knowledge and skills from previous courses. They asked that instructors "relate new topics to previously learned ones", "build on past knowledge", and stop "Using technical jargon to explain new topics that are already complex to begin with". They appreciate it when instructors "don't just speak to slides", explain "topics in different ways", and give them "a few minutes to ponder a solution roadmap for examples". All of these comments seem to indicate a self-efficacy in the learners, given a supportive learning environment.

Part of that support comes in the form of the resources and materials provided to the students. Lecture notes are very much appreciated and in some cases demanded. Comments range from "Thank you to those who put up their completed lecture notes or incomplete notes that can be expanded upon well before the lecture" to "Philosophically, I believe that it is the responsibility of every professor to reproduce good notes reliably in electronic format for his students", with most falling somewhere in between. Students appreciate clarification and/or summaries of what topics are important and where they should focus their energies. One student summed it up saying "Provide a summary of each unit along with what you are expected to know, replicate, and understand well".

Many students indicated a dislike for the way in which their instructors present and pace a lecture. Comments like "having a prof read off of a slide when I can just do that at home is a waste of my time and their time", slides that are "too convoluted and sometimes irrelevant to the points the profs are trying to orally make" and "fully premade slides don't encourage learning" indicate that students value their time and appreciate well organized and presented classes. Other comments suggest alternate methods may be useful for their learning, asking for "More visual examples to better demonstrate material. Many students learn better that way rather than just normal notes", suggesting instructors incorporate "many types of media", and provide "external resources that would help (us) understand the current topic".

Students also identified the value that other forms of support have on their overall experience. Academically, students appreciate instructors who provide "a brief overview of topics that will be covered in the lecture at the start of class", provide "Progressions in class 
(building material on top of past material, relating old concepts to new ones)", and don't move "too quickly through content or practice problems".

Students do not want instructors to tell them that "a lot of people don't pass their class. This is not something to be proud of". Students seem to appreciate instructors who consider how difficult it can be for students to absorb new and complex concepts as shown in comments like "Going through the material slowly and making sure the students understand the material", and "The best profs will occasionally give students breaks during the lecture, especially during 75 minute lectures. It helps students to refocus and stay on topic longer overall, instead of burning students out by the end of the lecture. It's the difference between running a marathon non-stop and running a marathon but walking when you need to so you can keep up the pace required to finish".

The majority of comments related to supported instruction reinforce that the undergraduate engineering experience is predominantly teacher-centred. Within that learning environment students appreciate well organized classes that recognize them as learners who need to see value in the content. They welcome all forms of academic support that their instructors can provide.

\subsection{Quality of Teaching}

Approximately $13 \%$ of all coded items related to the teaching practices, teaching quality, and instructional clarity of the instructor. Three themes emerged from these items: (1) the personality and personal characteristics of the instructor, (2) the thoroughness of the teaching, and (3) handwriting class notes.

Students perceive that instructors who are respectful, approachable, and have good communication skills make a difference in their overall success. This is enunciated by comments like the teacher "was friendly, had the attitude of wanting to help students succeed, admitted mistakes, was very open to student questions and answered them well, spoke clearly and loud enough", "The professor was enthusiastic and cared about the success of his students. Tests were fair, but not easy. The professor showed respect to his students. Participation was encouraged in class, but not to an extent where time was wasted", and "The prof card (sic) about the students and really wanted everyone to be as passionate about the course as he was. He made the course focused on the experience of the students rather than the marks".

Students perceive value in well-organized, learneraware classes delivered by enthusiastic and passionate instructors. One comment summed up myriad others in "This was an 8 am class, on a topic that I didn't plan to study further, and I was still excited to go on most days. The professor for this course was clearly passionate in the area he was teaching and took time to plan out his teaching to promote student understanding. His classes were laid out logically, and paced reasonably. He brought in humorous examples and ensured that, throughout the lecture, he was gaging student understanding and adapting his style to them. He would repeat as needed and keep going when students understood, and made time to answer all questions completely as they arose. He was also very open about going to him for questions outside of class, even for questions related more to other courses than the one he was teaching. He took the time and effort to actually focus on the students in his class learning the material and having it make sense."

Finally, many students prefer instructors to hand-write notes in class. Comments like "Only some do this, but physically writing the notes helps a lot" and "When profs write the notes with the class instead of powerpoints it helps with pacing" show that students feel it helps to regulate the pace at which the content is delivered. They also perceive it as a way to improve their understanding as noted in "writing the notes as they go over lecture content, answering student questions, doing practice problems with us". The quality of that writing was also a concern, and summarized by one student who wants instructors to stop "rushing too quickly to write things down with messy handwriting, please write neatly even if it takes an extra few seconds/minutes, especially in a large lecture room with hundreds of students looking at a small projector/chalkboard".

These student perceptions about the instructor seem to reinforce that the person at the front of the room has a significant impact on the learning potential of students.

\subsection{Remaining Themes}

It is difficult to extract any useful insights from the students' perceptions related to the remaining themes. Less than $3 \%$ of the coded items related to student engagement. The remaining $1 \%$ of coded items included those related to academic rigour, faculty-student relationships, and miscellaneous other perceptions.

\section{DISCUSSION}

This study explored what undergraduate engineering students believe contributes to, or impedes, their learning experience. It provides the missing data on the students' perceptions of their educational environment, a need identified by van den Bogaard [14]. The data is explored using the framework of effective learning as measured through the benchmarks of effective education practices. It highlights three key findings:

1. classroom practices are predominantly teacherdirected and lecture based

2. a dichotomy exists between students' desire to thrive and their need to survive

3. the instructor has a significant impact on student learning 
It is clear from both the students and the literature that lecturing is "deeply embedded in the culture of teaching in higher education" [19][20][21]. It appears that engineering students expect to be taught or have been conditioned to be passive learners by their instructors who overwhelmingly choose to lecture [12]. This shows a clear alignment between what Canadian engineering educators indicate they are doing in the classroom and what the students perceive as normal. There is, however, a disconnect between what is reportedly happening in the classroom and the focus on learning that is vital for effective learning. Trigwell, Prosser, and Waterhouse suggest that moving from a transmission-based delivery to an environment where students are directly involved in, and with, their learning could help establish a more effective learning environments [22].

The overarching goal of effective educational practice is to increase student success and add value to learners' experiences [3][4]. There has to be an appropriate level of academic rigour [10] and a focus on learning in order for students to really be successful. This study, however, shows an imbalance between the number of instructionalrelated comments about things done "for" the students $(68.1 \%)$ and the number of learning-focused comments (15.7\%). Many student comments imply a true desire to learn; they want to apply relevant content in authentic applications, and to learn expert strategies and practices in a supportive environment. Unfortunately these desires are countered by myriad pleas for opportunities to practice "the exact thing that will get them the marks". Contemporary theories of motivation suggest that providing students with learning opportunities that are perceived to have value, offer autonomy, and encourage self-efficacy can help balance the desire to thrive with the need to survive [23]. This can also help students move from sub-optimal motivational outlooks where they are disinterested in, overwhelmed by, or feel obliged to attend classes, to more optimal outlooks where students see value in attending classes, appreciate what they might learn, and link the benefits of attending class to longerterm academic or career goals [24].

Both the literature and these students' perceptions indicate that the instructor makes a difference in the learning environment. Epting and her colleagues suggest that "ideal" professors make themselves accessible to their students, consider the student voice in course policy and procedures, offer a variety of learning opportunities, and provide a comfortable learning environment [25]. Rossetti and Fox extend that work, stating that outstanding professors demonstrate presence and caring, promote learning, keep their teaching practices current, and are enthusiastic and passionate about teaching [26]. Students want to be taught by respectful, passionate, prepared, and organized educators who care about their success.

Until the educational practices in the undergraduate engineering classroom become more closely aligned with those of an effective learning environment, it is expected that engagement results for undergraduate Canadian engineering students will remain lowest of the disciplines [5]. To remedy this, educators can help students move from survival mode to an optimal motivational outlook [24]. They can also consider the finding of a metaanalysis of 225 studies in mathematics, science, and engineering that shows moving to a more student-centred, learning-focused environment can increase student performance and reduce failure levels [21]. The evidence is there but, as with any change, there must be dissatisfaction with the status quo. Resistance can come from administrators, educators and even the students themselves. It can be cultural, social, organizational, or psychological in nature [27]. Until stakeholders begin to question the implied acceptance of the traditional teachercentred, lecture-based experience reported in this study, there may be little change in the culture and traditions of the engineering classroom.

There is a possibility that the findings of this survey have a bias associated with non-response. Those students who chose to complete the survey may have different views from those who did not. This may limit the generality of the results of this study [28]. It is also not known what other factors may have contributed to their response or non-response. As a result, the following findings should be considered in the context of the limitations of this study.

\section{CONCLUSIONS AND FUTURE WORK}

Extensive research defines the benchmarks used to measure effective educational practices environments in higher education. This research adds insights from the students' perspective that can help engineering educators create learning environments in which students can balance their desire to thrive and learn with their need to survive in an academically rigorous program. Student views suggest that a more active and supportive studentcentred learning environment would be beneficial to their learning and academic success. They want to be taught by passionate, prepared and thorough instructors who treat them professionally and care about their success.

This research lays the foundation for further study. Work could be done to examine what engineering students are actually doing to be successful in their studies. This could help establish the motivational outlook through which students approach their studies and make recommendations on ways to raise or keep that outlook in the optimal zone. Additional research could be done to determine if undergraduate engineering students are 
intentionally or inadvertently being conditioned as passive learners. This work should include an examination of the educational practices used during the first year of study. Finally, work could be done to determine the impact of using the strategies identified in this study to establish effective learning environments for undergraduate engineering students.

It is hoped that adding the findings of this research to the existing body of evidence on effective learning environments will encourage engineering educators to establish learning environments where undergraduate students can efficiently balance their desire to thrive and learn with their need to survive the rigours of engineering.

\section{Acknowledgements}

This research study is funded by the National Sciences and Engineering Research Council of Canada (NSERC) and approved by the University of Calgary Conjoint Faculties Ethics Board. Special thanks to the engineering students who took the time to complete this survey, and the peer reviewers for their time and invaluable feedback.

\section{References}

[1] Great Schools Partnership, "Learning Environment," Glossary of Education Reform, 2013. [Online]. Available: https://www.edglossary.org/learningenvironment/. [Accessed: 28-Jan-2019].

[2] J. D. Bransford, A. L. Brown, and R. R. Cocking, How People Learn: Brain, Mind, Experience, and School. Washington, DC: National Academy Press, 2000.

[3] G. D. Kuh, J. Kinzie, J. H. Schuh, and E. Whitt, Student success in college: Creating conditions that matter. San Francisco, CA: Jossey-Bass, 2005.

[4] H. Coates and A. C. McCormick, Eds., Engaging university students: International insights from system wide studies. Springer, 2014.

[5] National Survey of Student Engagement, "Engagement Insights: Survey Findings on the Quality of Undergraduate Education - Annual Results 2018," 2018.

[6] Quality Indicators for Learning and Teaching, "2017 Student Experience Survey: National Report," 2017.

[7] UNISTATS, "The National Student Survey (NSS)," 2018. [Online]. Available: https://unistats.ac.uk/findout-more/National-Student-Survey-(NSS). [Accessed: 28-Jan-2019].

[8] R. H. Stupnisky, A. BrckaLorenz, B. Yuhas, and F. Guay, 'Faculty members' motivation for teaching and best practices: Testing a model based on selfdetermination theory across institution types," Contemp. Educ. Psychol., vol. 53, pp. 15-26, 2018.

[9] V. Tinto, "Enhancing student success: Taking the classroom success seriously," Int. J. First Year High. Educ., vol. 3, no. 1, pp. 1-8, 2012.

[10] J. Draeger, P. del Prado Hill, L. R. Hunter, and R. Mahler, "The Anatomy of Academic Rigor: The Story of One Institutional Journey," Innov. High. Educ., vol. 38, no. 4, pp. 267-279, 2013.
[11] G. D. Kuh, J. Kinzie, J. H. Schuh, and E. Whitt, Assessing conditions to enhance educational effectiveness. San Francisco, CA: Jossey-Bass, 2005.

[12] N. Nelson and R. Brennan, "Snapshot of engineering education in Canada," CEEA Conf. Proc. 2018, pp. 1$10,2018$.

[13] L. Harvey, "The sense in satisfaction," Times Higher Education Supplement, p. 29, 1999.

[14] M. van den Bogaard, "Explaining student success in engineering education at Delft University of Technology: a literature synthesis," Eur. J. Eng., vol. 37, no. 1, pp. 59-82, 2012.

[15] W. Boles and K. Whelan, "Barriers to student success in engineering education," Eur. J. Eng. Educ., vol. 42, no. 4, pp. 368-381, 2017.

[16] A. Hoon, E. Oliver, K. Szpakowska, and P. Newton, "Use of the 'Stop, Start, Continue' method is associated with the production of constructive qualitative feedback by students in higher education," Assess. Eval. High. Educ., vol. 40, no. 5, pp. 755-767, 2015.

[17] J. George and J. Cowan, A Handbook of Techniques for Formative Evaluation: Mapping the Student's Learning Experience. London, UK: Routledge, 1999.

[18] A. Meyer, D. H. Rose, and D. Gordon, Universal Design for Learning: Theory and Practice. Wakefield, MA: CAST Professional Publishing, 2014.

[19] W. Cerbin, "Improving student learning from lectures.," Scholarsh. Teach. Learn. Psychol., vol. 4, no. 3, pp. 151-163, 2018.

[20] D. Rose, W. Harbour, C. S. Johnston, S. Daley, and L. Abarbanell, Universal Design for Learning in Postsecondary Education, vol. 19, no. 2. 2006.

[21] S. Freeman et al., "Active learning increases student performance in science, engineering, and mathematics," Proc. Natl. Acad. Sci., vol. 111, no. 23, pp. 8410-8415, 2014.

[22] K. Trigwell, M. Prosser, and F. Waterhouse, "Relations between teachers' approaches to teaching and students'approaches to learning," High. Educ., vol. 37, p. 57079, 1999.

[23] D. A. Cook and A. R. Artino, "Motivation to learn: an overview of contemporary theories," Med. Educ., vol. 50, no. 10, pp. 997-1014, 2016.

[24] S. Fowler, Why motivating people doesn't work... and what does: the new science of leading, energizing, and engaging, 1st ed. San Francisco, CA: Berrett-Koehler Publishers, Inc., 2014.

[25] L. K. Epting, T. E. Zinn, C. Buskist, and W. Buskist, "Students perspectives on the distinction between ideal and typical teachers," Teach. Psychol., vol. 31, no. 3, pp. 181-183, 2004.

[26] J. Rossetti and P. G. Fox, "Factors Related to Successful Teaching by Outstanding Professors: An Interpretive Study," J. Nurs. Educ., vol. 48, no. 1, 2009.

[27] J. B. Ellsworth, Surviving Change - A Survey of Educational Change Models. Syracuse, NY: ERIC Clearinghouse on Information and Technology, 2000.

[28] L. J. Sax, S. K. Gilmartin, and A. N. Bryant, "Assessing Response Rate and Nonreponse bias in Web and Paper Surveys," Res. High. Educ., vol. 44, no. 4, pp. 409-432, 2003. 